This item was submitted to Loughborough's Research Repository by the author.

Items in Figshare are protected by copyright, with all rights reserved, unless otherwise indicated.

\title{
Causal mapping and scenario building with multiple organisations
}

PLEASE CITE THE PUBLISHED VERSION

PUBLISHER

(C) Elsevier

VERSION

AM (Accepted Manuscript)

LICENCE

CC BY-NC-ND 4.0

REPOSITORY RECORD

Goodier, Chris I., Simon A. Austin, Robby Soetanto, and Andrew R.J. Dainty. 2019. "Causal Mapping and Scenario Building with Multiple Organisations”. figshare. https://hdl.handle.net/2134/6033. 
This item was submitted to Loughborough's Institutional Repository (https://dspace.lboro.ac.uk/) by the author and is made available under the following Creative Commons Licence conditions.

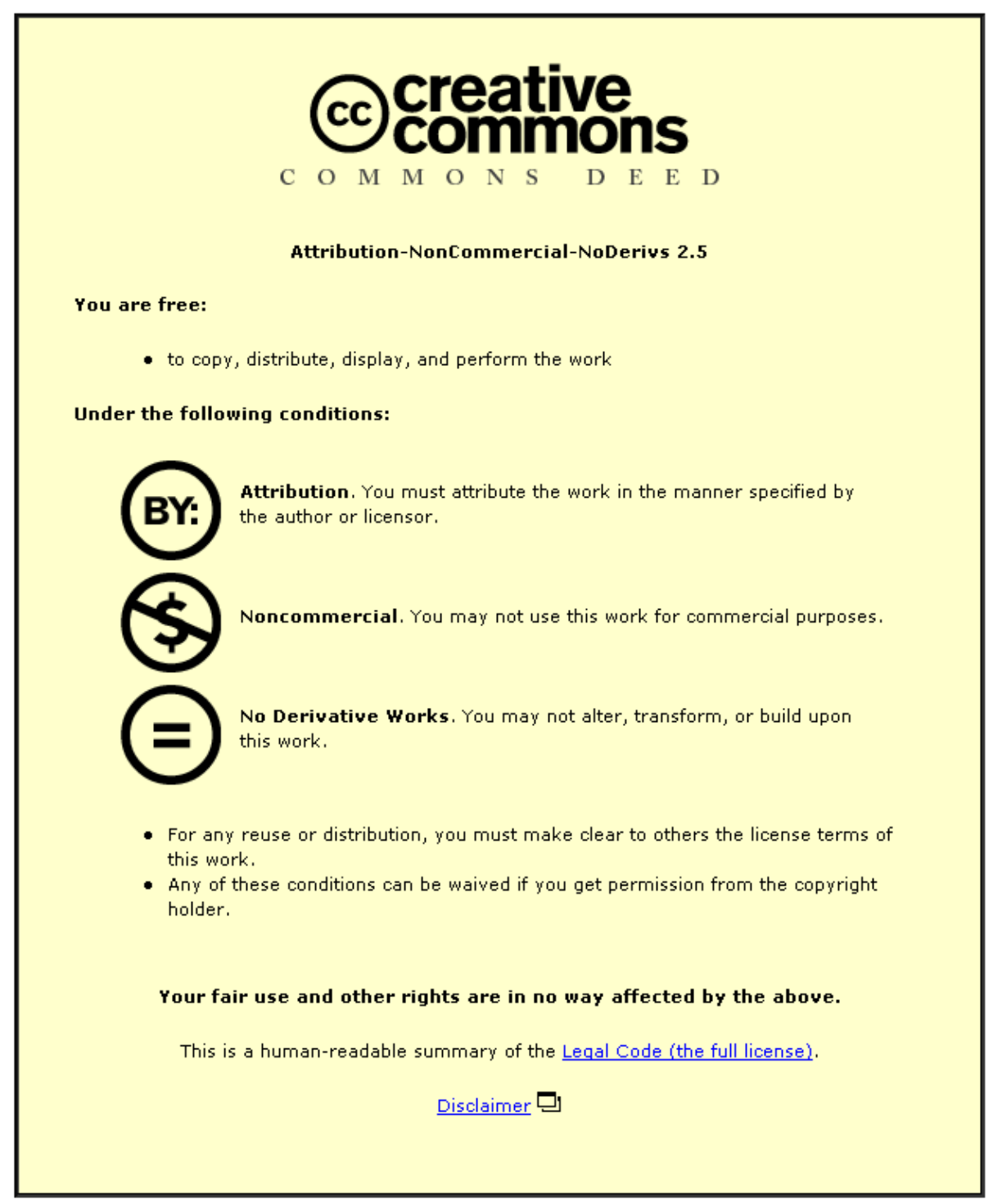

For the full text of this licence, please go to: http://creativecommons.org/licenses/by-nc-nd/2.5/ 


\title{
Causal mapping and scenario building with multiple organisations
}

\author{
Chris Goodier $^{\mathrm{a}^{*}}$, Simon Austin ${ }^{\mathrm{a}}$, Robby Soetanto ${ }^{\mathrm{b}}$, Andrew Dainty $^{\mathrm{a}}$ \\ ${ }^{a}$ Department of Civil and Building Engineering, Loughborough University, Loughborough, LE11 \\ 3TU, UK \\ ${ }^{\mathrm{b}}$ Department of the Built Environment, Coventry University, Coventry, CV1 5FB, UK \\ * Corresponding author. Tel +44(0)2476 887710, Fax +44(0)2476 888296, E-mail address: \\ c.i.goodier@coventry.ac.uk and chrisgoodier@email.com
}

\begin{abstract}
Thinking and planning for the future is critical in a competitive business world. Scenarios are a common technique for investigating the future, but can be time-consuming and challenging to develop, particularly when more than a single organisation is involved. An approach is presented here which shifts the focus of scenario building from the company level to the sector level, whereby a range of organisations engage collectively on a topic of mutual importance. A rapid technique was developed, with simple scenarios being constructed in 2 to 4 hours. This process was implemented in 13 multi-organisational workshops with participants from the construction and building industries, sectors which are traditionally short-term and reactive in their outlook. The resulting feedback, observations and experiences are discussed, together with examples of how the resultant scenarios have been applied. An example of causal map reflection (exposing an individual's causal map to others) is also presented, described and critiqued. It was found that the process was successful in engaging participants in thinking about and discussing the future, appreciating the interconnectivities of the related issues, and understanding the collective implications of their potential decisions, as well as facilitating the socialisation of participant thinking and the construction of collective futures.
\end{abstract}

\section{Keywords}

Causal mapping, scenario building, multiple organisations, cognitive mapping, construction industry

\section{Introduction}

Many of today's problems cut across disciplines and sectors, particularly in industries as broad and diverse as construction. 'Joined up' thinking and avoiding 'silo mentalities' are advocated as necessities for cross-sectoral working, progress and innovation. However, for both practical and historical reasons, expertise traditionally remains concentrated within sectors or disciplines. Relatively few examples exist of construction companies engaging in futures studies and our research has revealed a marked reluctance to plan for the long term due to the relative volatility of the market and a perceived lack of control over factors external to the organisation which dominate [1-5]. The work presented here builds upon the existing body of futures methods and studies, but focuses on cross-organisational perspectives and an understanding of the interdependency of factors and potential future pathways.

Construction is an example of a sector which has frequently been berated for its poor performance and lack of forward thinking (e.g. [2,6]). The industry is often perceived as lagging behind in adopting new technologies, working practices and processes [3]. Recent futureoriented reports and studies have called for the construction industry to expand their planning horizons by looking beyond their next project to help prepare themselves for potential future events and trends $[1,4]$. However, construction organisations are highly dependent on externalities, often with complex inter-dependency. Perhaps as a result, most construction companies are reluctant to engage in planning beyond a few years and there is little evidence of a formal process in the formulation of long-term strategies, or even to reflect on the long-term. This is often attributed to inadequate resource capacities, instability of employment, the unpredictability of the construction market, and the predominance of small-sized companies operating within the sector $[7,8]$. 
Construction companies do however, design and build (and increasingly manage and operate) buildings and infrastructure that will be used many decades into the future. In a context of rapidly changing business, technological and environmental conditions it can therefore be argued that an understanding of the future should be a fundamental requirement of this sector. Some examples do exist, in the form of future scenarios for a place (e.g. [9]), a technology (e.g.[10]), or a sector (e.g. $[11,1])$, but are rarely used to inform strategy. This contrasts with other sectors that routinely use scenario planning and other futures techniques to help shape their long-range planning (see [12], and [13]). Basic strategic planning is conducted in some construction organisations, but very rarely incorporates any form of futures techniques, and is more likely to rely on SWOT or PESTEL/STEEP type analyses $[8,14,15]$.

Futures studies are sometimes perceived as an attempt to foresee the future. Prediction is not the purpose however - their usefulness is in helping organisations prepare for an uncertain future by producing possible scenarios and identifying potential risks and opportunities in order to inform strategic decision making $[16,17]$. This is the focus of the approach presented here. The process also helps to extend the future-thinking orientation of industry practitioners, thus facilitating intra- and cross-organisational learning and understanding.

The research presented here investigated the building of future scenarios around an issue that cuts across the sector (rather than around a company/firm or organisation), by representatives from 3 to 4 organisations. An industry-focused scenario-building process is therefore presented, based upon causal mapping, which is akin to the creation of shared cognitive maps of the participating construction professionals. The process is rapid and focussed, with the scenarios being generated in 2 to 4 hours. The approach was implemented with 65 groups in 13 workshops and the resulting feedback and lessons learnt explained. Feedback on the causal maps and scenarios from a new audience is also described. Comparisons are made with existing scenario building methods, the benefits and lessons learnt are evaluated, and further improvements are considered.

\section{Studying the future}

A range of quantitative and qualitative techniques have been applied in the area of future studies $[18,19]$. The methods which underpin the process presented in this paper are cognitive (or causal) mapping and scenario building.

\subsection{Mental models and causal mapping}

Mental models provide a framework for the interpretation of events or phenomena in life [13]. They are particularly useful when investigating groups where coherent and coordinated behaviours and actions are critical. People need to communicate and negotiate intentions and plans, which in turn, will be moderated by the other members of the group. Cognitive maps can illustrate mental models by a simple graphical representation of a person'(s) thinking, that locates the person(s) in relation to their informational environments $[20,21]$. These are sometimes called 'concept' or 'causal maps' and the latter term is employed here to mean a map that exhibits people's perception of a causal network of relationships in a form of nodes and paths [13]. A causal map is a particular type of concept or cognitive map. While a concept map only indicates that ideas or concepts are related in some way, a causal map illustrates the cause and effect relationships among concepts. Nodes contain future issues, factors, events or outcomes whereas paths (arrows) describe the causal relationships between them. Eden and Ackermann [13] proposed a way of structuring the map according to a tear-drop or pyramid shape, with the desired outcome (or goal) at the top, and the strategies, key issues, supporting factors and options at a lower level.

Fiol and Huff [20] identified three main components of cognitive mapping, namely:

1. identity (identify key actors, events and processes);

2. categorisation (the interrelationships of the actors, events and processes); and

3. cause and argument (the potential interconnections amongst entities of the importance to the organisation through time, i.e. the 'route').

The identity and categorisation components provide the inputs for the causal and argument components. Corporate strategic decisions are often made through a process of individual negotiation, in which idiosyncratic views, interpersonal relationships and politics all have an 
influence. The combining of causal maps can help facilitate this negotiation by reconciling goals, merging issues, factors and events, and validating interconnectivities and pathways to the future Eden and Ackermann [13,22]. Merged maps should also maintain a balance between unity and diversity - lack of unity leads to a dysfunctional map, whereas lack of diversity negates creative production of alternative views of the future, and may also stifle innovation [20].

\subsection{Scenario building}

The production of causal maps can both be a stepping stone to producing future scenarios. A scenario can be described as a storyline comprising a range of interconnected and uncertain future events and their possible consequences. They often support decision making in which some parameters are uncertain or poorly defined [17]. They thus present perceptions of alternative environments in which decisions and actions might be played out [8]. Scenarios are not about predicting events or determining the most likely scenario, but developing several credible stories of the future that describe how the environment in which an individual or organisation lives or operates may develop, given certain future events, trends or developments.

Scenarios are one way of addressing the unreliability of prediction by the description of a number of possible futures (e.g. [23,17,24,25]). Broadly speaking, these exponents of futures methodologies advocate the general philosophy of: exploring multiple and uncertain futures; taking into account qualitative factors and the roles of actors; considering information and forecasts are value and context-laden; opting for a plurality of approaches; and adopting a global and systemic approach [17]. It is typical to create 3 to 4 alternative accounts of the future.

For scenarios to be informative and useful to practitioners, and/or to hope to give a plausible (and credible) account of the future, it helps if there is a relationship with current conditions and practices i.e. if they are grounded in the reality of the present. Without an appreciation of events that have preceded the situation or the influence that people who may influence, it would be difficult for the scenarios to be connected to the strategies generated to respond to or pre-empt them [4].

Timescales vary considerably. O'Brien [26] discusses a time horizon of just five and ten years, whereas other, more recent scenarios, have horizons of 16 years [9] or even 50 or more years $[1,11]$. Collins and Porras [27] stated that "companies need an audacious 10-to-30 year goal to progress toward an envisioned future". Hiemstra [12] found that taking a long-range view of about 20 to 25 years is best for corporate planning because this permits people to imagine that things will be different, to make fundamental changes in their organisations, and to seize opportunities that are not given by shorter views (of, for example, 3-5 years). It is common sense that the scanning horizon should be aligned with the factors under consideration and the lifecycle of the venture; however, most authorities stress the need to stretch the participants thinking and hence recommend a timescale at the long end of the sensible scale, which can help break down mindsets that are naturally wedded to the shorter term.

Scenarios can provide a framework to develop and evaluate corporate strategies, hence the notion of a 'test drive' of strategic decisions. However, there is little evidence of this within construction organisations, who are predominantly short-term and reactive in their outlook but generally able to respond quickly to changes in their business environment. Little evidence therefore exists for the use of (or need for) traditional long-term scenario planning in construction companies $[7,8]$.

\subsection{Multi-organisational scenario building}

Approaches exist which bring together diverse disciplines and sectors for the purpose of multisector project planning, an example being Cairns et al [28] who used scenario building to help attenuate inter-organisational fragmentation, enabling new and creative insights and collective foresight to be agreed. Their method "converted the tacit knowledge of individuals into explicit group knowledge.....that enabled sense to be made of seemingly conflicting and contradictory ideas". They used it as an enabling mechanism for strategic conversation with broad-based stakeholder involvement, and as a "basis for forming consensus views on issues, whilst maintaining conflict", whilst acknowledging that "there may be problems of continuing exclusion and fragmentation driven by powerful stakeholders". Schoemaker [29] built multiple scenarios with broad organizational input as a practical way to stretch and expand participants thinking collectively and individually. Participants were asked "to consider conjunctions of events (as opposed to isolated ones)" in order to enhance a scenario's credibility. The negatives however, 
included a "relatively steep learning curve" for workshop participants and the challenge of how to "move from scenarios to strategies, plans and budgets".

Other problems also exist - Wälti and Kübler [30] identified the danger in inter-organisational scenario building where organisations or individuals form internal alliances within the workshop groups and seek to pursue solutions based upon their own agendas, rather than seeking a group consensus. Eden and Ackermann [22] also identify a risk of the realities of the problem situation being ignored and "group-think" occurring. The danger is that the group then negotiates a course of action that nobody wants and that nobody knew the others didn't want it. Multipleorganisational futures approaches are also not just used in scenario building - Kemp-Benedict and Agyemang-Bonsu [31] identified the significant cross-sectoral benefits of a climate change adaptation strategy in Ghana by using a simplified cross-impact analysis approach. Eppler and Platts [32] suggest that the use of cognitive mapping as a visualisation tool can also bring cognitive, social and emotional benefits. The process can facilitate the socialisation of an individual participant's thinking domain and the construction of collective futures [33].

We conclude that the facilitation of conversations about futures issues which may affect a range of organisations has potential as a means of engagement and shifting the timescales of individual's thinking. In particular it could be well suited to the assessment of external factors which might impact across the supply chain.

\subsection{Scenario building processes}

Many scenario building processes and frameworks exist. The origins can be traced back to Shell [34], and this influenced much of the early methodological development. In particular, Linneman and Kennell's [35] 'shirt-sleeve approach' was adopted by many, with slight adjustments based on the work of Schnaars [16]. The resulting methodology was primarily a top-down, qualitative sequence of steps whose aim was to produce a scenario 'snap-shot' in time at a particular date in the future. The original method presented by Linneman and Kennell [35] consisted of five key steps, namely:

1. Set the scene (who for and time horizon).

2. Generate and select factors (typically 12 factors using a PEST analysis).

3. Choose themes and develop scenario details (between 2 and 4 scenarios developed by 'projecting' each factor within each scenario).

4. Check consistency of scenarios (using a cross impact analysis).

5. Develop and test strategies that would be robust under each scenario.

O'Brien [26] identified a number of common pitfalls when applying this approach including: the predictability of a limited set of factors and the theme selection; a focus on current/next big issues; making implicit assumptions; and an unimaginative presentation of scenarios. His revised method introduced modifications such as generating up to 40 uncertain (as well as predetermined) factors which are then clustered, reduced and ranked in terms of uncertainty and importance to the organisation.

Korte and Chermack [36] recently presented a scenario building process as a tool to help change organisational culture, based upon the work by Schwartz [37] which used shared mental models:

1. Identify key issue or aim for the organisation.

2. Identify key factors by interviewing people within the organisation.

3. (Externally) research driving forces.

4. Rank key factors and driving forces according to importance, potential impact and uncertainty.

5. Develop scenario logics along two axis.

6. Develop scenario details using key factors and driving forces.

7. Consider scenario implications (i.e. test strategies).

8. Identify leading indicators for monitoring the scenarios and how they will impact the organisation. 
This process combines interviewing key people within an organisation with researching external driving forces and therefore takes several independent stages to complete. The advantage being however, that the process reconciles the opinions of key people within an organisation with the external driving forces in which they and their organisation operate, whether they are aware of them or not.

The inter-organisational scenario building used by Cairns et al [28] also involved interviews with key decision makers, but from across a range of organisations. Content analysis of the interview transcripts was used as the basis for a strategic conversation workshop, the output of which provided the theme for a subsequent scenario workshop. 150 driving forces were generated by the workshop participants and "intuitive logics" were used to explore causal relationships and to reduce the number of forces to a limited number of high level issues, two extremes of which were used as the axes for the generation of four future scenarios.

Within construction, Brightman et al. [8,38] developed the Construction Alternative Futures Explorer (CAFÉ), a computer-based decision support tool for scenario development and causal mapping based upon the Decision Explorer ${ }^{\mathrm{TM}}$ software. The scenarios were developed using semi-structured interviews, around which the scenarios were built. Related issues were then identified and clustered by the research team and fed back to the company for verification. Additional interviews with relevant external experts and literature reviews were then conducted to develop the scenarios. These were then finalised in a company workshop setting, either with or without the CAFÉ support tool. CAFÉ used a combination of traditional scenario planning and causal mapping, but the uniqueness was that the software was adapted for "presenting, structuring and analysing" the cognitive data. CAFÉ used information from trade publications as the basis for their maps, which was then presented to workshop participants for discussion and critique. As Brightman et al [8] acknowledged, care had to be taken to justify the inclusion of one piece of information over another, particularly when information appeared to contradict one another. Senior managers interviewed also admitted that their IT capabilities were "universally poor" and that there was even "antipathy" towards the use of a computerised process. Indeed, Brightman et al [8] admits that "the leap between the data presented and the development of a number of clearly defined, company-specific scenarios was not adequately achieved during this session". The process also involved several interventions over a considerable length of time, with interviews and workshops with company staff required.

\subsection{Causal map reflection}

Eden and Ackermann [21,22] suggested a way of exposing an individual's causal map to others through a process of 'negotiating' and/or 'merging'. 'Negotiation' occurs when two or more causal maps are going to be integrated by stakeholders during a decision-making process and often involves 'merging', where two concepts are amalgamated into one in the presence of informants and/or interviewers. Disagreement on language and semantics can often prove problematic, as can a lack of shared experiences relevant to a particular domain [39]. A technique of generating, integrating and checking a causal map's consistency was proposed by [40]: "In practice, consistency testing is often carried out in a qualitative and sometimes implicit way, e.g. by using expert panels to get critique and suggestions for improvement."

Reflection workshops are best employed to allow participants to reflect on the issues and their interconnectivities within a causal map and what the implications are for individuals, organisations and/or sectors. Anecdotal and 'harder' evidence of the issues and their interconnectivities can be identified to enrich the maps and allow deeper (interpretive) analysis.

\subsection{Scenario building for construction organisations}

The methods outlined above, though rigorous, can take considerable time for both the participants in the workshop, and for the analytical work by the research team. The majority of the steps require the research team to carry out additional investigative and/or writing work before the next step can begin. This assists the production of a set of robust and rich scenarios, but it also means that the participants can sometimes be left unsatisfied after each session as they have to wait days, or even weeks, before they see the fruit of their endeavours. Gaining repeated access to senior managers, especially for more than a few hours at a time, is often difficult. In a modern fast-moving workplace time is at a premium, and decisions have to be made quickly - time is not always available to devote to detailed scenario building or to the windtunnelling of company policies. 
Most scenario approaches also focus on a single company, involving a number of senior managers, with the aim of producing a series of scenarios which can be used to help inform or test company strategy. This is a traditional aim of scenarios, although there is little evidence of this being done in construction. There are occasions however, when a senior manager will want to investigate the potential future(s) of a specific topic or issue, in order to help inform their decision making, rather than the future of their company. He/she may also be interested in the views and opinions of influential parties. Indeed, it can be of particular benefit for parties to come together to discuss the future of a particular topic - to understand one another's point of view and plan a way forward, be it individually or collectively. This situation is of particular relevance to the construction industry, which has been repeatedly berated for its confrontational nature and lack of collective working and understanding $[3,41]$. A new process is therefore presented here which shifts the focus of scenario building from the single company level to that of a common issue facing the sector.

\section{Causal map based process}

Two approaches to developing multi-organisational perspectives were developed. The first was based upon traditional approaches, namely a series of workshops to produce rich visions of four scenarios using the 'double axes of uncertainty' approach popularised by Schwartz [37] (widely used by the UK government Foresight programme $[1,11]$ ), together with associated time lines, a desired future and resulting action plans, and these are reported elsewhere [42].

The second process, presented here, offers a complimentary approach of short, focussed, oneoff multi-organisational workshops using causal mapping, inter-connected pathways and participant plenary session to produce alternative future scenarios around a common theme. This was developed in response to the need for a methodology which could quickly generate a group of scenarios, completed in 2 to 4 hours (or even less), and which could be used to provide a basis for potential inter-organisational policy debate on a particular topic or theme.

A key element of both approaches was the combination of initial brainstorming of issues and factors by the participants, together with the introduction by the facilitators of pre-prepared lists of factors related to the selected scenario theme. The latter were extracted by the research team from a detailed review of 15 recent construction-related future reports, synthesised into a large matrix which clustered the factors into themes whilst retaining the source and original language $[43,4,5]$.

The process was designed to create causal maps which could illustrate the 'cause and effect' relationships between the factors and outcomes (usually articulated as events) set against a rudimentary time line of 10 to 20 years and hence facilitate a debate and the identification of possible pathways. It was restricted to 2 to 4 hours, as opposed to 2 to 3 days (or longer).

Where several groups participated as set of future scenarios for a particular theme emerged. The ten steps in Table 1, along with Figure 1, describe the stages of the causal map scenario building process.

Table 1. Causal mapping workshop process

Figure 1. A digitised causal map: 'Increasing knowledge management and information sharing'

\section{Applications and Observations}

A total of 244 people, in 13 workshops took part in this scenario building process, representing 47 companies, 16 organisations and lobby groups, and six academic institutions. Themes covered have included social (e.g. aging population, demographics), economical (e.g. globalisation, whole life costing), environmental (e.g. climate change, sustainability) and 
technological (e.g. automation, materials). The majority were organised jointly with UK construction institutions including the Institution of Civil Engineers (ICE) and the Construction Industry Confederation $(\mathrm{CIC})$ and generated a total of 65 causal maps and associated textural scenarios were produced.

\subsection{Application}

The scenarios have been applied in a variety of ways. On the one hand they have precipitated academic enquiries into specific themes, namely skills, housing, energy, procurement and technology which are being published via journals [44,45,42], and a book [46]. But opportunities have also been taken to inform industry initiatives. Constructing Excellence used the output of their scenario workshop to help bridge the gap between where the industry is now and where they wanted it to be and hence inform their current industry development and improvement policies.

The BRE'sii roadmap for the future of waste and resource efficiency was informed by six of the scenarios and associated causal maps, as part of the scenario workshop process [47]. They helped the participating organisations look forward imaginatively to identify where they wanted to be and what were the potential barriers and opportunities. Themes investigated were in the area of buildings and sustainability, including adaptable buildings, energy efficiency, recycling, whole life costing and reducing waste.

ConstructionSkillsiii identified key issues and changes from the mapping process, which the UK construction industry could encounter over the next 10 to 20 years. This led to an assessment of the future implications for employment, skills and training requirements [48].

\subsection{Causal map reflection and aggregation}

Eden and Ackermann [13,22] suggested a way of exposing an individual's causal map to others through a process of 'negotiating' and/or 'merging', and this technique was investigated as part of this work. This idea was explored through an industry workshop with five groups of between five and six participants each. The research team combined six causal maps related to skills into a single map amalgamating common events and issues. Six embedded pathways of causal relationships were then extracted for debate and assessment that cross-sectioned two or more individual maps and formed a credible scenario. See Soetanto et al [44] for further explanation.

Breaking down the combined map into smaller pathways reduced the complexity for the workshop participants in a situation where maintaining interest on causal maps created by other people can be problematic [13,p.329].

\footnotetext{
'Constructing Excellence, a cross-sector, cross-supply chain, member-led organisation for the UK construction industry, www.constructingexcellence.org.uk

ii Building Research Establishment Ltd, a consultancy, testing and commissioned research services company in the UK covering all aspects of the built environment, www.bre.co.uk iii ConstructionSkills, the UK Sector Skills Council and Industry Training Board for UK construction industry, www.cskills.org
} 
Each group was given one pathway and members individually:

1. ranked each event/issue/factor with regard to its probability (High, Medium or Low);

2. modified the wording of existing issues/events/factors (if required); and

3. challenged the logic of the interconnections between the events/issues/factors, modifying them and/or inserting intermediaries.

The group then debated similarities or discrepancies to obtain consensus. They were asked to identify formal or anecdotal evidence to support the revised pathway and discuss ways in which their different organisations might prepare. The five groups' presented in a plenary session for additional debate and questioning.

\subsection{Defining the theme}

It proved important to let participants modify the theme to reflect what they thought was important - some found "the [original] theme ..., a little bit restricting" or that it conflicted with their views. One suggested that "rather than a sentence [for the theme], maybe [offer] some key words" It often took the some time to get started on the causal map, sometimes due to failing to agree the theme or being unclear what was required or how to begin. A (sometimes uneasy) compromise on the theme wording sometimes had to be made in order to progress with the task. The themes suggested were deliberately broad to provide flexibility but this sometimes created uncertainty in what to concentrate on. Clear instructions and facilitation proved essential for the maps to be completed in the allotted time. Participants also found it valuable if the themes investigated by different groups were connected, so that cross-cutting issues could be identified and a bigger picture revealed. It was therefore vital to leave sufficient time for the plenary debate.

Participants differed in their opinion regarding groups investigating the same issue, with some participants preferring this to then "fully debate differences and similarities", whilst others preferred to map separate issues around a common theme and then to "compare, contrast and debate."

Thought should be given to the allocation of participants to themes. Given a choice, people gravitated towards subjects on which they were experts - this can produce rich causal maps, but sometimes unimaginative scenarios would result. The alternative of arbitrarily delegating the themes can produce novel ideas, but also lead to frustration and weak, poorly detailed causal maps.

\subsection{Constructing the map}

The workshop process was regarded an improvement on the sticky labels brainstorming exercises commonly experienced. The process of constructing a network of interrelationships improved understanding of the context and consequences of possible future events and actions, and of the particular pre-requisites required for certain events and/or desired outcomes to take place. These benefits and the associated sharing of understanding did however take slightly longer and were intellectually more demanding.

Some found it difficult to think about future events and issues in the future, understandably when construction organisations rarely plan further than 3 to 5 years ahead. The process however, did provide a helpful framework to encourage and stimulate participants to discuss the future, and unrealistic speculations were moderated in the group setting. A small number resisted the individual brainstorming because "I can work on my own at home" and "I'm here to discuss these issues", which required effective facilitation.

Many issues suggested were trends (e.g. ageing population, global warming) not events and so were difficult to place on a timeline. This could be overcome by converting the trend into an event e.g. 'the number of retired people doubles compared with the year 2000'. The timeline was explained to be more of a framing device, where feedback between events was acceptable (even encouraged) generating a series of nodes and associated interconnections rather than a timeline.

Some participants found it easier to 'ladder down' than 'ladder up' (though this was not always the case). This depended upon the chosen theme, timeline and/or the goal/outcome, as well as the personalities within the group. 
A number of participants inevitably discussed issues not relevant to their topic and others found it difficult to agree how factors, goals or connections should be placed on the map. This reiterates the need to emphasise the benefits of the process in stimulating debate and shared understanding.

Care had to taken with the timing of introducing the additional factors from the analysis of expert reports - too early influenced initial brainstorming, and too late and the participants had completed their factor identification and did not want to consider other possibilities. It was found that participants usually introduced only one or two additional factors from the analysis of expert reports, if at all, instead usually relying mainly upon their own knowledge and judgment.

Competent facilitation was essential to ensure that participants followed the structured methodology, but at the same time had sufficient freedom and flexibility to discuss and debate specific issues of interest throughout the process. Ensuring that all the participants within all the workshop groups were sufficiently engaged and that none of the groups were dominated by a single strong personality was an additional challenge, a factor identified by Cairns et al [28].

The majority of the 65 causal maps produced within the workshops were of good quality defined here as presenting intelligible, credible pathways and interesting insights. Twelve contained no or few connections, were partly ineligible and/or contained poorly described content. This was due to a combination of inadequate time, disinterest and weak facilitation. Such poor outcomes could be minimised by ensuring sufficient time for the workshop (2-4 hours), that the participants want to be there and have been properly briefed, and providing experienced facilitation.

\subsection{Participant reflection on the causal maps}

Some participants struggled with reflecting on causal maps developed by other people, as was suggested by [13,p.329]. This was usually due to a combination of lack of interest in the topic, and/or misunderstanding of, or disagreement with, the wording of the issues. Participants were generally much more interested in generating their own ideas, and thought they could produce a 'better' map. In contrast, some participants found it enjoyable to "see what other people have said before" which sometimes invigorated the debate, often concentrating on disagreements with the original map. It was also clear that if the causal map contained a significant number of issues or links then it became confusing and time consuming to understand and comment upon in the limited time. Discussion frequently focused on loose or nebulous terminology - it was therefore important that words such as 'large', 'important', 'sustainability' or 'climate change' were avoided if possible, unless accompanied by a more detailed explanation. The process was found to have particular utility in exposing any potentially weak causal maps and at expanding interesting, but under-developed stories.

\subsection{Novelty of the process}

The process presented here offers several advantages over traditional scenario building approaches such as those described by Linneman and Kennell [35], O'Brien [26] and Korte and Chermack [36], as well as the construction-focussed process outlined by Brightman et al. [8]. These are concerned with duration, focus and multi-organisational perspective, as described below.

\subsubsection{Length of workshop}

Many traditional approaches to scenario generation can take considerable time and require the research team to carry out additional work before the next step. The method presented here is considerably quicker, and can be completed by an experienced facilitator in 2 to 4 hours, the longer workshops generally producing richer, more robust maps and associated scenario pathways. The short duration does however require a relatively steep learning curve for participants, a factor also found by Schoemaker [29]. This process generates quickly a group of scenarios which can be used in their own right, or as a basis for future discussion or investigation.

\subsubsection{Issue/topic focussed}

Traditional scenario approaches are commonly focussed on a single company with the aim of producing a series of scenarios which can then be used to help inform, or test company strategy. The process presented here has raised awareness of potential future events around specific themes and help break out of short-term mindsets to inform decision making. The themes chosen were usually of interest to, or potential influence on, the future of a firm or firms, 
but the causal map and scenarios generated were more specific than traditional scenarios and have therefore been used in a different way. The process however, can also be used to help the development of more company-specific future scenarios, as explained in Soetanto et al. [49].

\subsubsection{Multi-organisational groups}

The process can help a mixed participatory group of individuals, companies, interest groups and/or stakeholders to collectively generate alternate scenarios. These mixed groups could be, for example, project-focussed (e.g. a client, designer and contractor for a new building), themefocussed (e.g. a professional institution, training provider and major employer to discuss training and qualifications) or involve a particular part of the supply chain. The process has been shown to enhance shared understanding and can identify potential problems, differences of opinion or 'bottlenecks' along desirable pathways and to identify a way forward between a group of interested parties on a particular theme.

\section{Summary}

Whereas many forward-thinking industry practitioners are able to identify current (and near future) important issues and events, they are often poor at even acknowledging interdependencies, never mind identifying the potential consequences. Most expert 'thinkers' stay within their sphere of knowledge, and have poor relative appreciation of advances in related areas. This conservatism is often exacerbated, especially in the construction industry, by the need to operate within strict industry and government codes and regulations which can often stifle creative and futures-orientated thinking. Identifying and exploring interconnected events will help to extend practitioners sphere of thinking, facilitate communication amongst key stakeholders, and enhance understanding of the context within which their strategic decision making takes place.

It also appears that the beneficiaries of a move towards the long view would not only be clients and the public (where it is a sine non qua for sustainable development) but also the construction sector itself, which needs to better prepare for its own future, through the creation of a more informed and forward-thinking environment, accumulating and capturing the knowledge of its diverse participants, in order to stimulate creative thinking.

The scenario building process presented here takes elements from previously developed processes $[36,26,35,8,28]$, but develops it further and applies it in practice to multiple organisations within the construction industry. It is designed to produce causal maps and alternative future pathways on a specific issue chosen by the participants, who can be a mixed interest group, rather than representatives from a single organisation. Our experiences suggest that it has potential to enhance the capability of construction organisations to cope with the dynamic and uncertain nature of the sector, as well as being applicable to other rapidly changing sectors.

The process is considerably quicker when compared than most other approaches but strong facilitation is required, to avoid poorly-defined and conceived outputs. It can generate quickly a group of scenarios which can be used in their own right to investigate a particular challenge or as a basis for future investigations, several examples of which have been included here. The workshop process was regarded as an improvement on the common sticky label brainstorming exercises had been experienced previously.

Perhaps unsurprisingly the value of the process was as much in the process of their production as the creation of the maps and scenarios themselves. This echoes the contribution of Eppler and Platts [32] that the process will not only produce systematic causal maps, but importantly brings cognitive, social and emotional benefits to the participations and organisations involved. The approach was found to be helpful in enhancing understanding of how contributing factors operate and interconnect within the sector, and hence provides a basis for potential interorganisational or company policy debate. The process was successful in engaging participants in: thinking about and discussing the future, appreciating the interdependency of the issues, and understanding the implications of their potential decisions. 


\section{References}

[1] Foresight (2008), Sustainable Energy Management and the Built Environment, final report, The Government Office for Science, London, www.foresight.gov.uk.

[2] DTI (2001) Constructing the Future, Foresight report, Built Environment and Transport Panel, Construction Associate Programme, Department of Trade and Industry, London.

[3] Egan, J. (1998) Rethinking Construction, HMSO, UK.

[4] Harty, C., Goodier, C.I. Soetanto, R., Austin, S.A., Dainty, A.R.J. and Price, A.D.F. (2007) The Futures of Construction: a critical review of construction futures studies, Construction Management and Economics, 25(5), 477-493.

[5] Goodier, C.I., Soetanto, R., Dainty, A.R.J., Austin, S.A., Price, A.D.F., Harty, C., (2007) A competitive future for UK construction?, Construction Information Quarterly, Vol.9, Issue 4, Dec. 2007, p169-174,.

[6] Fairclough, J (2002) Rethinking Construction Innovation and Research: a review of Government R\&D Policies and Practices, Department of Transport, Local Government and the Regions, UK.

[7] Edum-Fotwe, F. (1995) A framework for improving the strategic management of construction contractors. Unpublished PhD thesis, Loughborough University, UK.

[8] Brightman, J.R., Eden, C., van der Heijden, K. and Langford, D.A. (1999) The development of the construction alternative futures explorer, Automation in Construction, 8, pp.613-623.

[9] Dublin Chamber of Commerce (2004) Imagine Dublin 2020, www.dubchamber.ie, pp16.

[10] Clarke, M. (2006) Precast concrete and masonry- 40 years on, Concrete, July 2006, p66-67.

[11] Foresight (2006) Foresight Intelligent Infrastructure Futures, Office of Science and Technology, DTI, London, DTI/Pub 8155/2k/01/06/NP. URN 06/521, www.foresight.gov.uk.

[12] Hiemstra, G., (2006), Turning the Future into Revenue, John Wiley \& Sons, Hoboken, New Jersey, USA, p173, ISBN 978-0-471-79293-2.

[13] Eden, C. and Ackermann, F. (1998) Making strategy: the journey of strategic management. Sage Publications Ltd., London.

[14] Betts, M and Ofori, G (1992) Strategic planning for competitive advantage in construction. Construction Management and Economics, 10(6), 511-532.

[15] Price, A.D.F. (2003) The strategy process within large construction organisations. Engineering, Construction and Architectural Management, 10(4), 283-296.

[16] Schnaars, S.P. (1987) How to develop and use scenarios, Long Range Planning 20(1), 105-114.

[17] Godet, M. (2000) The Art of Scenarios and Strategic Planning: Tools and Pitfalls, Technological Forecasting and Social Change (65), 3-22.

[18] Fowles, J. (ed.) (1978) Handbook of futures Research. Greenwood Press, London.

[19] Helmer, O. (1983) Looking Forward A Guide to Futures Research. Sage, London.

[20] Fiol, C.M. and Huff, A.S. (1992) Maps for managers: Where are we? Where do we go from here? Journal of Management Studies, 29(3), 267-285.

[21] Eden, C. and Ackermann, F. (2001a) SODA - the principles. Rational Analysis for a Problematic World Revisited: Problem Structuring Methods for Complexity, Uncertainty and Conflict, 2nd edition, Rosenhead, J. and Mingers, J. (eds.), John Wiley \& Sons Ltd, Chichester, UK.

[22] Eden, C. and Ackermann, F. (2001b) Group decision and negotiation in strategy making. Group Decision and Negotiation, 10, 119-140.

[23] Berkhout, F. Hertin, J. \& Jordan, A. (2002) Socio-economic futures in climate change impact assessment: using scenarios as learning machines, Global Environmental Change, (12), 83-95.

[24] Kok, K. Rothman, D. and Patel, M. (2006) Multi-scale narratives from an Al perspective: European and Mediterranean scenario development, Futures, (38), 261-284. 
[25] Rotmans, J. van Asselt, M. Anastasi, C. Greeuw, S. Mellors, J. Peters, S. Rothman, D. \& Rijkens, N. (2000) Visions for a sustainable Europe, Futures, (32), 809-831.

[26] O'Brien, F.A. (2004) Scenario planning - lessons for practice from teaching and learning, European Journal of Operational Research, 152, 709-722.

[27] Collins, J.C. and Porras, J.I. (1996), Building your company's vision, Harvard Business Review September-October 65-77.

[28] Cairns, G., Wright, G., Van der Heijden, K., Bradfield, R. and Burt, G. (2006) Enhancing foresight between multiple agencies: Issues in the use of scenario thinking to overcome fragmentation, Vol. 38, Issue 8, Oct. 2006, p1010-1025.

[29] Schoemaker, P.J.H. (1993), Multiple Scenario Development: Its Conceptual and Behavioral Foundation, Strategic Management Journal, Vol. 14, No. 3, p193-213.

[30] Wälti, S. And Kübler, D. (2003), "New Governance" and Associative Pluralism: The Case of Drug Policy in Swiss Cities Policy Studies, Policy Studies Journal, Vol. 31 Issue 4, p499 - 525.

[31] Kemp-Benedict, E. and Agyemang-Bonsu, W.K., The Akropong approach to multi-sector project planning, Vol. 40, Issue 9, Nov. 2008, p834-840.

[32] Eppler, M.J. and Platts, K.W. (2009) Visual strategizing: the systematic use of visualization in the strategic-planning process. Long Range Planning, 42, 42-74.

[33] Fuller, T. and Loogma, K. (2009) Constructing futures: a social constructionist perspective on foresight methodology. Futures, 41, 71-79.

[34] Wack, P. (1985) Scenarios: shooting the rapids. Harvard Business Review, 63(6), 139-150.

[35] Linneman, R.E. and Kennell, J.D. (1977) Shirt-sleeve approach to long-range plans, Harvard Business Review 55 (12), 141-150.

[36] Korte, R.F. and Chermack, T.J. (2007) Changing organizational culture with scenario planning, Futures, doi:10.1016/j.futures.2006.11.001

[37] Schwartz, P. (1996) The art of long view: planning for the future in an uncertain world, Currency, New York.

[38] Brightman, J.R., Eden, C., van der Heijden, K. and Langford, D.A. (2002) CAFÉ user's guide, version 1.2. Banxia Software Ltd., www.banxia.com/dexplore/cafe.html

[39] Langfield-Smith, K. (1992) Exploring the need for a shared cognitive map. Journal of Management Studies, 29(3), 349-368.

[40] Börjeson, L., Höjer, M., Dreborg, K.H., Ekvall, T. and Finnveden, G. (2006) Scenario types and techniques: towards a user's guide. Futures, 38, 723-739.

[41] Latham, M. (1994) 'Constructing the Team', Department of the Environment, HMSO, UK.

[42] Goodier, C.I., Austin, S.A. and Guthrie, W. (2009), Future scenarios for the European Construction Industry, accepted for publication, ARCOM conference, www.arcom.ac.uk, Nottingham, 7-9 ${ }^{\text {th }}$ Sept. 2009, UK.

[43] Soetanto, R., Dainty, A.R.J., Goodier, C.I., Harty, C.F., Austin, S.A., Price, A.D.F. and Thorpe, A. (2006) Synthesising emerging issues within key futures study reports in construction. Construction in the XXI century: Local and global challenges, Proc. of Joint Int. Symp. of CIB W55, W65 and W86, Rome, 18-20 Oct., pp. 308-309 (Exec summary). ISBN 88-495-1339-9

[44] Soetanto, R., Dainty, A.R.J., Goodier, C.I., Austin, S.A. (2009), Enhancing the understanding of the complexity of the future construction skills crisis, submitted to Futures.

[45] Guthrie, W., Dainty, A.R.J., Goodier, C.I., Austin, S.A., and Soetanto, R. (2009), Housing Futures: dealing with complexity and competing agendas, submitted to Housing Studies, undergoing revision.

[46] Goodier, C.I., Austin, S.A., Soetanto, R., Dainty, A.R. and Guthrie, W. (2009), Looking to the future -scenarios for construction, book, in writing, Blackwells Publishing, UK.

[47] Hobbs, G. (2008), Construction Resources and Waste Roadmap, prepared by BRE for Defra's Business Resource Efficiency and Waste Programme (BREW), www.crwplatform.org.uk and www.bre.co.uk/page.jsp?id=805, 44pp. 
[48] ConstructionSkills (2008), 2020 Vision - The Future of UK Construction, May 2008, 97pp., report by Experian and SAMI Consulting for ConstructionSkills, www.constructionskills.net/ and www.samiconsulting.co.uk

[49] Soetanto, R., Goodier, C.I., Austin, S.A., Dainty, A.R.J. and Price, A.D.F. (2007) Scenario planning for construction companies, presented at Construction Management and Economics 25th Anniversary Conf., 16-18th July 2007.

[50] Ackermann, F., Eden, C. with Brown, I. (2005) The practice of making strategy: A step-bystep guide. London: Sage Publication Ltd. ISBN 0761944931.

[51] Evans, J. R. (2005) Total quality management, organization, and strategy (4th ed.), Mason, $\mathrm{OH}$ : Thomson South-Western.

[52] Scavarda, A.J., Bouzdine-Chameeva, T., Goldstein, S.M., Hays, J.M. and Hill, A.V. (2006) A methodology for constructing collective causal maps. Decision Sciences, 37(2), 263-283.

[53] Nijstad, B. A., Stroebe, W., Lodewijkx, H. F. M. (2003). Production blocking and idea generation: Does blocking interfere with cognitive processes? Journal of Experimental Social Psychology, 39, 531-548.

[54] Bryson, J. M., Ackermann, F., Eden, C., and Finn, C. B. (2004). Visible thinking: Unlocking causal mapping for practical business results. San Francisco: Wiley.

[55] Markbczy, L. and Goldberg, J. (1995), A Method for Eliciting and Comparing Causal Maps, Journal of Management, Vol. 21, No. 2,305-333.

[56] Sherwood, D. (2002), Seeing the Forest for the Trees, a Manager's Guide to Applying Systems Thinking, Nicholas Brealey Publishing, London, ISBN 1-85788-311-X, p274.

Table 1. Causal mapping workshop process 


\section{Choose theme and create groups}

The participants selected a theme from a pre-prepared list derived from a selection of recent construction-oriented futures reports and studies [43]. Providing alternatives helped generate ideas and ensured that participants had an interest in the chosen theme.

Participants were normally divided into groups of 2-4 with a variety of expertise. The number of groups varied but it was found that three or four groups per facilitator was a good balance between obtaining a range of scenarios and manageability. The wording of the theme was amended if this helped the group capture the essence or key question of the subject, and this was written on A1 paper.

\section{Decide causal map goal/outcome and timeline}

The maps were constructed against a horizontal timeline, spanning from the present day to the next 10 to 20 years, as chosen by the group, with the horizon of at least 10 years

recommended to break their thinking from the present.

The groups were asked to identify at least one industry goal or outcome associated with their theme (and, if more than one, to consider how they were linked i.e. to build a system of goals) [50]. These were then placed on the right-hand side, representing a point in the next 10 to 20 years, and the left hand side being the present day.

\section{Individually brainstorm issues, factors and barriers}

Participants generated individually 10 to 20 issues and factors (phrased where appropriate as events) that would influence their goals/outcomes over their chosen time-span. ${ }^{\text {iv }}$ These were written on sticky labels (if possible with an indication of when they thought it would happen) with specific terminology encouraged, including active verbs and direction of a trend. The current situation was then captured including, recent past events which implied some path dependency."

The key issues and factors could be either internal or external to the delegates' organisation, external being those related to political, economical, social, environmental and technological developments in their sector outside the influence of the organisation (e.g. government legislation and demographics). Internal issues and factors originate within the organisation, such as changing managing directors or entering new markets and are, to a large extent, controllable by members of the organisation. Participants were encouraged to think laterally and identify possible barriers or 'wild cards', in order to embrace a diverse range of possibilities.

\footnotetext{
iv According to Evans [51], "cause and effect diagrams are usually constructed in a brainstorming setting so that everyone can contribute their ideas."

${ }^{v}$ Individual brainstorming was preferred to capture independent views before working together - group exercises tend to be influenced by the strong personalities and can produce unproductive disagreements [52]. Group exercises can also work against junior staff who feel unable to express their view freely in the presence of their superiors. In addition, problems such as distraction, 'social loafing', evaluation apprehension, and production blocking can also inhibit individual as well as group, brainstorming $[53,54]$.
} 


\section{Place issues and factors onto the causal map timeline}

Participants placed their individually labels onto the timeline in the most appropriate location. Those for the current and recent events were placed on the left of the timeline. The space in between the 'goal/outcome(s)' on the right and this current situation was then populated with linking issues and factors leading to, or resulting from, the goal or current issue respectively. ${ }^{\text {vi }}$ Similar factors were clustered indicating consensus. ${ }^{\text {vii }}$

\section{Introduce additional issues and factors}

At this stage pre-prepared factors related to the theme were offered. These had been selected by the research team from an analysis of 15 recent construction future studies [4].The participants added relevant items they thought necessary but had not themselves generated. The purpose was to compliment their thinking with 'expert' views but not lead them, as likely if they were offered at the beginning. The accepted and rejected factors were recorded.

\section{Identify dependencies}

Cause-and-effect relationships were now debated and added (as arrows) to develop pathways and enhance a scenario's credibility [29]. These interconnectivities were either 'laddered up' (consequences of) or 'laddered down' (explanations of), whichever proved easier [13]. Inverse relationships were illustrated with a minus sign (i.e. more of A causes less of B) [55]. This is a feature in common with influence diagrams in system dynamics (SD).

A further feature of interconnection was the introduction of inter-dependent events (feedback loops). Whilst this was strictly speaking illogical between items displaced horizontally on a time line, it was encouraged to provide a richer expression of the system and potential iteration. These feedbacks and inverse relationships would help with the application of the causal maps in subsequent causal map and SD analysis [8,56].

\section{Challenge the map}

The participants challenged their map, checking its integrity, logic and continuity; items were moved around and revised if necessary. A check was made for: ambiguous terminology; inverse relationships (minus sign); disconnected items (orphans) removed if desired; and required additional issues or factors and interconnectivities.

\section{Identify pathways}

Scenarios were identified as distinct pathways through the interconnected factors from the present day to the envisioned future goal or outcome. At least two were identified by the participants to reflect uncertainties. Factors common to more than one scenario were noted. An emphasis was placed on finding stories with new and interesting insights, not the obvious scenarios. Alternate good and bad scenarios were also avoided, with credible scenarios usually consisting aspects of both.

\section{Plenary session and questions}

At the end of the workshop, a representative from each explained their chosen goal/outcome

\footnotetext{
${ }^{v i}$ An approach similar to that of Eden and Ackermann [13]

vii Sticky labels provide the necessary flexibility to move items as group debate and deeper thought adjusts opinion.
} 
and presented their scenario(s) as a story through time, highlighting key factors and barriers. This was recorded to allow post-workshop analysis along with the ensuing debate prompted by questions from other participants which also captured understanding of, and reaction to, each scenario.

10. Post-workshop production

The workshop data was converted into digital causal maps. ${ }^{\text {vii }}$ This and the recorded plenary formed the basis for a textural narrative scenario written by the research team. The map and text were sent to the participants for validation. 
